\title{
E-mails spark ethics row
}

The rapper Earl 'DMX' Simmons is not known for his conciliatory lyrics. So Tyrone Hayes, a biologist and faculty member at the University of California, Berkeley, drew from Simmons's lexicon earlier this year while writing a series of 'trash-talking' e-mails to representatives of Syngenta, the world's largest producer of the herbicide atrazine.

Those e-mails, which Hayes says were prompted by a heated encounter with a Syngenta scientist, are included in an ethics complaint that Syngenta filed with top University of California officials on 19 July. The Syngenta scientist concerned denies provoking Hayes. The action marks the latest in a series of bitter exchanges between the

Switzerland-based company

and Hayes, whose work has

linked atrazine to adverse effects on the environment and on human health.

Atrazine works by inhibiting photosynthesis in plants, but can disrupt endocrine pathways in animals. Although banned by the European Union, it remains one of the most widely used herbicides in the world, with tens of millions of kilograms applied annually to US farms and lawns.

In 2002, Hayes and his colleagues showed that developing male frogs exhibited female characteristics after exposure to atrazine $e^{1,2}$. In more recent work $^{3}$, he reports the same effect in an adult male frog of one species. The effects are observed at exposure levels deemed safe by the US Environmental Protection Agency (EPA). Hayes has also been a co-author on work that names atrazine as a potential cause of reproductive cancers in humans ${ }^{4}$. Syngenta casts doubt on all these claims. The company's website quotes EPA findings that cite methodological problems with Hayes's research and suggest that there is insufficient evidence to support his conclusions.

Mark Schlissel, dean of biological sciences at the University of California, Berkeley, says that the "decade long" dispute between Hayes and Syngenta has "moved increasingly into the personal arena". Hayes met with university officials on 6 August to discuss the latest incident, although Schlissel says that Hayes is not under investigation.

Syngenta asserts that Hayes's taunting and racy e-mails put him in violation of
Berkeley's ethical standards. In a letter to the university, the company acknowledges an "ongoing difference of opinion" with Hayes over atrazine, but states that the researcher has not responded to its attempts to interact with him "on a scientific level".

Hayes, who grew up in a tough South Carolina community, says he reacted to intimidation from Syngenta in a language and style he felt appropriate. "Where I came from, people did a lot more," he says.

This is not the first time Hayes has sent offensive e-mails to employees of Syngenta. Earlier missives sparked a complaint in February 2009. Berkeley responded with a letter to the company saying that Hayes had agreed to refrain from using offensive language in his communications.

Hayes, who says he was not aware of the university's response, told Nature that his latest e-mails were a reaction to a confrontation with a Syngenta scientist in Springfield, Illinois. Hayes was there to provide testimony on atrazine to the state's Environmental Health Committee, and words were exchanged between the two men shortly before Hayes spoke. Illinois representative Karen Yarbrough (Democrat), a committee member who was present, confirmed that an encounter occurred but did not know what was said.

Hayes's research has figured prominently in legal actions against Syngenta and other manufacturers of atrazine. The chemical is currently the subject of a class action lawsuit launched against Syngenta by 15 water providers in Illinois who are seeking at least \$350 million for facilities to purify drinking water of atrazine, which they say poses a threat to human health. Syngenta says such claims are false.

A similar suit involving 17 water providers across six Midwestern states is currently in progress in a federal court in East St Louis, Illinois. On its website, Syngenta says the cases are based on "questionable studies". Rex Dalton

1. Hayes, T. B. et al. Proc. Natl Acad. Sci. USA 99, 5476-5480 (2002).

2. Hayes, T. et al. Nature 419, 895-896 (2002).

3. Hayes, T. B. et al. Proc. Natl Acad. Sci. USA 107, 4612-4617 (2010).

4. Fan, W. et al. Environ. Health Perspect. 115, 720-727 (2007) 